\title{
What Does Network Theory Contribute to Theorization of Mathematics Teaching?
}

\author{
A Response to Elizabeth Mowat \& Brent Davis
}

DAVID KIRSHNER

Louisiana State University (USA

STEPHEN LERMAN

London South Bank University (UK)

THOMAS E. RICKS

Louisiana State University (USA)

Cognitive theory has for a long time struggled with the "frame problem" (Dennett, 1978; Fodor, 1983; Pylyshyn, 1987). More narrowly, the frame problem of classical artificial intelligence (classical AI) asks how a cognitive system can update its beliefs in light of the possibility that some may have been invalidated by its prior action. More broadly, the frame problem of cognitive science is nothing short of the problem of context; how to reflect computationally the fluid and spontaneous ways in which human agents deal with an environment that is ever in flux (SEP, 2009).

The problem arises in classical AI owing to the commitment to a logic-based symbolic representational treatment of all cognitive events. In the broader cognitive science community there is ongoing debate as to whether the relationship of cognizing agent to context ever can be adequately represented within these strictures (e.g., Brooks, 1999, 2002; Clancey, 1999). Theorists elaborating embodied cognition as well as a host of other theoretical departures (e.g., ecological psychology, situated cognition theory, social 
constructivism, connectionist theory) are voting "no" in their varied attempts to stake out alternative theorizations of cognition that, one way or another, depart from the orthodoxies of classical representation.

The landscape of representational alternatives is dense, indeed. Sometimes there is considerable overlap of perspectives across the labeled approaches. On the other hand, each label references not a single theoretical approach, but a family of related approaches. For instance, in response to an attack on situated cognition theory by Anderson, Reder, and Simon (1996) - paragons of classical AI-Greeno (1997) outlined situativity theory, a version of situated cognition that still retains some basic cognitivist assumptions (Kirshner \& Whitson, 1998), eventually reaching at least an uneasy truce with former antagonists (Anderson, Greeno, Reder, \& Simon, 2000). Similarly, embodied cognition theory has many different emphases, of which George Lakoff's (Lakoff \& Johnson, 1980, 1997; Lakoff \& Núñez, 2000) metaphorical mechanisms form just one strand (Anderson, 2003).

We introduce our response by contextualizing the project undertaken by Mowat and Davis (2010) (hereafter M\&D) to highlight how ambitious it is, and how contested is the terrain they seek to traverse in the marriage of metaphorical embodiment of mathematical concepts with network theory. Of course one need not submit to the discipline of psychology to explore embodiment. We know from Davis (1996) and Davis and Sumara (2006) that these authors are well versed in the phenomenology of Husserl, Heidegger, Merleau-Ponty, and van Manen for whom the richness of lived experience is the starting point, rather than a distant destination: "At the center of phenomenology is the notion of embodiment, ... [which] means not just having, and acting through, some physical instantiation, but recognizing that the particular shape and nature of one's physical, temporal and social immersion is what makes meaningful experience possible" (Anderson, 2003, p. 124). But M\&D have avoided all reference to phenomenologyclearly their goal is to contribute to the science of learning. As philosophers we may dismiss the logic-based symbolic representation of classical AI as unsophisticated. But as scientists, the classical AI folks have home-field advantage. With the possible exception of connectionism, none of the alternatives proffered thus far has come even close to classical AI in formulating explicit and testable cognitive hypotheses. This is the playing field that Mowat and Davis have chosen for their current effort.

So how well does M\&D measure up with respect to these lofty expectations? It is not our purpose in this responsive paper to offer a detailed or definitive evaluation. Rather, as our title promises, we are interested in the educational efficacy of M\&D-to which we turn in the second part of this article. But it seems worthwhile to spend at least a bit of ink up front to consider the prospects for the project more broadly.

\section{Metaphor and Metonymy}

A premise of M\&D, inherited from Lakoff and Núnez (2000) is that the metaphoric network of mathematics forms "the basis of mathematical knowledge and knowing" (Mowat \& Davis, p. 9). Lakoff, in his earlier collaboration with Mark Johnson (Lakoff \& 
Johnson, 1980, 1999), is rightly lauded for delving into the particularity of metaphor as fundamental to conceptuality. But linguists have long recognized the central importance of metaphor in tandem with metonymy:

Jakobson (1971) suggests that language can be characterized along two perpendicular axes, combination and selection, which he associates with metonymy and metaphor, respectively. The selection or metaphor axis consists of the processes of selection, substitution, and similarity. One must select the source domain, and then the relationships or structure within the source domain is substituted in the target domain, giving it structure. The relationships are based on the similarity of the two domains.

Along the combination or metonymy axis are the processes of combination, contextualization, and contiguity. Metonymy combines several parts of the domain and uses one part to represent them all; hence it is a process of combination. The metonymic relationship is based on ideas which are related or connected within the same conceptual domain; thus it is a contiguous relationship. In contrast to metaphor, the relationships in metonymy are based on the contiguity of the ideas not the similarity of their structure. (Zandieh \& Knapp, 2006, pp. 3-4)

Walkerdine (1982) elaborates on the distinction in terms of embeddedness in an existing practice:

Metaphor provides an opening into the use of a particular discourse. ... Young children reason when a task is, to use Margaret Donaldson's term, 'embedded', because they can examine what is permissible within the particular practice which is called up by the metaphoric significance of that task.

Formal reasoning ... involves conscious reflection by the subject on ... the internal relations of combination of the metonymic axis. In practical reasoning we determine the truth or validity of a statement in terms of its correspondence to the rules of practice, whereas in formal reasoning truth is determined in terms of the internal relations of the statement itself. To reflect on the internal relations alone we have to ignore the metaphoric content of a statement which might distract from the focus on the logical relations entailed in the statement. (pp. 137-138)

Now, Lakoff and Núñez (2000) do assign a role to metonymy, interpreting it as the linguistic device that enables a label to stand in for a particular entity: In the sentence "When the pizza delivery boy comes give him a good tip, ... 'pizza delivery boy' comes to stand metonymically for the individual who fills the role" (p. 74). In this capacity, they see metonymy as fundamental to the use of variables in algebra; variables stand in for unspecified individual numbers (p. 74). But this interpretation only uses metonymy directly as a linguistic device in the same way that metaphor often is interpreted merely as a linguistic device. Of course, the whole point of Lakoff's writing in this vein is to broaden that interpretation, for metaphor (Holcombe, 2007). ${ }^{1}$

${ }^{1}$ Lakoff and Johnson (1980) pay a bit more attention to metonymy: "Metonymy...has primarily a referential function, that is, it allows us to use one entity to stand for another. But metonymy is not merely a referential device. It also serves the function of understanding. For example, in the case of metonymy the part for the whole [traditionally called synecdoche] there are many parts that 
It seems to us this relative neglect of the metonymic axis places more of a burden on the metaphoric axis than it can reasonably bear. For instance, following Lakoff and Núñez (2000) M\&D rely on the notion of "conceptual blends" in theorizing the emergence of new meanings: "new concepts are formed as domains fuse and create conceptual blends" (p. 9). An example is development of analytic geometry through application of the Cartesian plane to the circle (see Figure 10 in M\&D). In fact, this juxtaposition of otherwise unrelated signifiers seems to exactly characterize metonymic rather than metaphoric processes. There is no reason to suppose this blend to have been conceptually motivated, but rather to be inspired by the juxtaposition of the systems of signification, themselves. By framing such blends as metaphor-driven M\&D weaken the concrete sense of meaning making that makes metaphor so appealing and potentially useful for educators. Conversely, the reduction of all meaning making to metaphoric connection seems to us to betray a fundamental characteristic of meaning making - in mathematics, especially.

Could the M\&D framework be broadened to "The Metaphoric and Metonymic Network of Mathematics?" For purposes of pedagogical theorizing such a move probably would be advised. It would enable us to maintain the pedagogical implications already achieved for metaphor while adding further possibilities for metonymy. However, to the extent network theory is being proffered as a genuine theoretical contribution to the science of learning, this move might complicate the theory irremediably. It is beyond the scope of this article to assess this question on its technical merits.

\section{Constructivist and Sociocultural Influences on Mathematical Pedagogy}

The marriage of conceptual metaphor with network theory creates a duality discernable throughout the paper between the concrete particularity of specific metaphors and the more open characterization of non-linear and emergent network processes. Instances of the former include extensive discussion of particular metaphors such as "motion along a path" and "rotation by 180"” (Figure 4; see also Figures 5 and 6). The more open-ended characterization of network processes is illustrated in the widely eclectic mix of elements presumed to constitute the concept of CIRCLE and CONTAINER including conceptual, visual, lexical, auditory, tactile, kinesthetic, and emotional elements (Figures 2 and 3). These elements are presumed to interact with one another within the ecology of network processes, but in ways that are not deterministically specifiable. Later on, elements become organized within subnetwork levels (Figure 7). But these are not to be understood primarily as logical hierarchies, the point being that the topology is scalefree, highlighting structural similarity rather than functional differentiation.

A parallel duality can be found in the educational implications in M\&D. The educational implications are oriented around ways to decrease the likelihood of a

can stand for the whole. Which part we pick out determines which aspect of the whole we are focusing on." (p. 36). Still, this does not elevate the dynamic function of metonymy on a par with metaphor. 
breakdown in understanding interpreted in network terms as "cascading failure" (p. 25). We note in passing that this interpretation of conceptual breakdown, as far as we are aware, is a new one for mathematics education, one that we find highly suggestive and appealing - a promising contribution to the mathematics education literature.

In order to diminish the likelihood of such breakdown, M\&D recommend increasing network connectivity:

Increasing the number of connections among conceptual domains would have the desired effect of reducing the network's dependence on its hubs. Adding even a few links between clusters of nodes decreases the network's vulnerability. (p. 23)

Within this overall approach we notice two distinct strategies. Strategy 1 might be summarized as Select Metaphors Wisely (SMW), as reflected in the following passage: “ARITHMETIC AS MOTION ALONG A PATH would be more useful in this context ... [than] the ARITHMETIC AS OBJECT COLLECTION metaphor, ... [as] the OBJECT COLLECTION metaphor cannot deal with situations where the addition of integers leads to smaller sums" (p. 24). Similarly, the advice given on page 24-5 regarding the desirability of specific grounding metaphors for addition and multiplication indicates SMW. Strategy 2 is the general heuristic advice to Increase Metaphorical Connections (IMC): "introducing a variety of metaphors in classroom activities to provide inferential structure for as many aspects of a concept as possible is vital for the establishment of such new connections, and for ensuring rich and complex subnetworks for mathematical ideas" (p. 25).

We relate this duality in M\&D to the bifurcation in education between a focus on individual acquisition of knowledge products and a focus on structures of participation. Sfard (1998) captures this bifurcation in her characterization of two metaphors-the Acquisition Metaphor (AM) and the Participation Metaphor (PM)-that she sees as driving theorists' pedagogical interests across the educational spectrum:

"Participation" is almost synonymous with "taking part" and "being a part," and both of these expressions signalize that learning should be viewed as a process of becoming a part of a greater whole. ... Just as different organs combine to form a living body, so do learners contribute to the existence and functioning of a community of practitioners. While the AM stresses the individual mind and what goes "into it," the PM shifts the focus to the evolving bonds between the individual and others. While AM emphasizes the inward movement of the object known as knowledge, PM gives prominence to the aspect of mutuality characteristic of the part-whole relation. (p. 6)

In theoretical terms, these foci are often framed by psychological constructivist tradition of concept analysis and sociocultural interest in the character and quality of classroom engagement, respectively (Cobb, 1994). Constructivism highlights the teacher's role as a facilitator of particular conceptual understandings in the classroom. We see this as consistent with M\&D's interest in ensuring students make particular metaphorical connections to mathematics content. Socioculturalism highlights the teacher's concern for the processes of engagement (understood as more than engagement among students to include also forms of engagement with the content itself, Kirshner, 2002). We see this as consistent with M\&D's interest in creating a metaphor-rich learning environment-in 
orienting students toward metaphorical engagement with mathematical content as an instructional goal in itself.

In short, M\&D's two pedagogical strategies (SMW and IMC) seem to us to fit within the basic structure of existing pedagogical discourse. However, within this structure M\&D do contribute novel elements. Tracing back to the Piagetian origins of (psychological) constructivism, concepts typically are understood as coherent structures of schemas (e.g., Thompson, 1994). Research into such structures typically is pursued in constructivist Teaching Experiments (Steffe \& Thompson, 2000) that clarify the conceptual terrain students are to traverse. In turn, such analyses can provide a foundation for development of a "Hypothetical Learning Trajectory" (Simon \& Tzur, 2004) within which the teacher holds specific expectations for how students' understandings will be transformed through engagement in a task environment. We think of this as a "high maintenance" pedagogical format on account of the strenuous demands it places on both teachers and students.

In contrast to a coherent structure of schemas, M\&D's concepts tend to dissolve (or perhaps, fracture) into an array of metaphorical elements. ${ }^{2}$ This dissolution of concepts makes constructivist Teaching Experiments and Hypothetical Learning Trajectories unlikely supports for instruction. M\&D do not provide much specific guidance for implementing SMW beyond just introducing, explaining, and exploring the selected metaphors. We cannot predict how, and how effectively, this program of instruction would play out, but it clearly represents a comparatively "low maintenance" way to address students' attainment of specific conceptual understandings, one that is worthy of careful study by the mathematics education community. We should note that pedagogical implications stemming from the SMW strategy really derive from the characterization of metaphor in Lakoff and Núnez's (2000) work, rather than directly from the engagement with network theory introduced in M\&D. But even this is a new contribution, as Lakoff and Núñez did not pursue educational implications in their book (Presmeg, 2002).

On the participation side related to the IMC strategy, there is really no specific guidance given beyond the barebones advice to incorporate lots of metaphors in instruction. The theoretical implication is that more metaphorical connectivity strengthens networks of understanding. Whereas this seems like reasonable advice, we do not get an intuitive feel from M\&D as to how the density of connections - apart from consideration of the particular metaphors chosen-would influence student learning. But the idea seems worth exploring, as do the forms of classroom participation that might implement such a plan.

In summary, M\&D can be appreciated and evaluated on two levels. Our major focus has been at the level of pedagogical utility. Our major finding is that these authors have introduced a provocative, interesting, and potentially very useful characterization of conceptual breakdown in network terms as "cascading failure." We look forward to

\footnotetext{
2 "More than one source is required to illuminate such rich domains, each metaphor describing a different aspect of the complex target" (Mowat \& Davis, 2010, p. 13).
} 
engagement with this idea from the significant areas of scholarship concerned with cognitive obstacles and conceptual change. We also found the outline of a new pedagogical focus on metaphor in mathematics instruction. This focus seems to incorporate strategies that address learning mechanisms offered by psychological constructivism and sociocultural theory (we might summarize these as equilibration and mediation respectively) that have dominated in pedagogical theorizing in mathematics education in recent decades. It will be important to continue to refine these pedagogical strategies and to examine their potential for achieving long-held goals for student learning.

To a lesser extent we have focused on the potential contribution the marriage of network theory with embodied cognition might make to enduring problems of cognitive theory as related to the brittleness of the logic-based symbolic representations of classical AI. At this level, we have raised some concerns about the possible overemphasis on metaphor at the expense of metonymy as a fundamental construct that M\&D have inherited from Lakoff and Núñez (2000) (reflected also in Lakoff \& Johnson, 1980, 1999). Though our expertise is not sufficient to resolve the questions we've raised at this level, we do want to acknowledge the general intellectual integrity of Mowat and Davis' research into embodied metaphor and network theory. Often scholarship in educational psychology seems to us to start from an implicit pedagogical vision that is elaborated and justified through theory. In this case, we get the impression that Mowat and Davis are pursuing the conjunction of network theory with embodied metaphor with no preset pedagogical agenda, but rather looking to the theory itself to suggest pedagogical departures. Only this kind of scholarship can be truly transformative for educational practice.

\section{References}

Anderson, J. R., Greeno, J. G., Reder, L. M., \& Simon, H. A. (2000). Perspectives on learning, thinking, and activity. Educational Researcher 29(4), 11-23.

Anderson, J. R., Reder, L. M., \& Simon, H. A. (1996). Situated learning and education. Educational Researcher 25(4), 5-11.

Anderson, M. L. (2003). Embodied cognition: A field guide. Artificial Intelligence 149, 91-130.

Brooks, R. (1999). Cambrian intelligence: The early history of the new AI. Cambridge, MA: MIT Press.

Brooks, R. (2002). Flesh and machines: How robots will change us. New York: Pantheon.

Clancey, W. J. (1999). Conceptual coordination: How the mind orders experience in time. Mahwah, N.J.: L. Erlbaum Associates.

Cobb, P. (1994). Where is the mind? Constructivist and sociocultural perspectives on mathematical development. Educational Researcher 23(7), 13-20.

Davis, B. (1996). Teaching mathematics: Toward a sound alternative. New York: Garland Publishing.

Davis, B., \& Sumara, D. (2006). Complexity and education: Inquiries into learning, teaching, and research. Mahwah, NJ: Lawrence Erlbaum Associates.

Dennett, D. (1978). Brainstorms. Cambridge, MA: MIT Press.

Fodor, J.A. (1983). The modularity of mind. Cambridge, MA: MIT Press.

Greeno, J. G. (1997). On claims that answer the wrong question. Educational Researcher 26(1), 5-17.

Holcombe, C. J. (2007). Metaphor: Theories. TextEtc.Com.Retrieved on December 27, 2009 from http://www.textetc.com/theory/ metaphor.html 
Kirshner, D. (2002). Untangling teachers' diverse aspirations for student learning: A crossdisciplinary strategy for relating psychological theory to pedagogical practice. Journal for Research in Mathematics Education 33(1), 46-58.

Kirshner, D. \& Whitson, J. A. (1998). Obstacles to understanding cognition as situated. Educational Researcher 27(8), 22-28.

Lakoff, G., \& Johnson, M. (1980). Metaphors we live by. Chicago, IL: University of Chicago Press.

Lakoff, G., \& Johnson, M. (1999). Philosophy in the flesh: The embodied mind and its challenge to western thought. New York: Basic Books.

Lakoff, G., \& Núñez, R. (2000). Where mathematics comes from: How the embodied mind brings mathematics into being. New York: Basic Books.

Mowat, E., \& Davis, B. (2010). Interpreting embodied mathematics using network theory: Implications for mathematics education. Complicity: An International Journal of Complexity and Education 7(1), 131.

Presmeg, N. (2002). Mathematical idea analysis: A science of embodied mathematics. Journal for Research in Mathematics Education 33(1), 59-63.

Pylyshyn, Z. W. (Ed.) (1987). The Robot's Dilemma: The frame problem in artificial intelligence. Ablex.

Sfard, A. (1998). On two metaphors for learning and the dangers of choosing just one. Educational Researcher 27(2), 4-13.

Simon, M. A., \& Tzur, R. (2004). Explicating the role of mathematical tasks in conceptual learning: An elaboration of the hypothetical learning trajectory. Mathematical Thinking and Learning 6(2), 91-104.

Stanford Encyclopedia of Philosophy (2009). Frame-problem. Retrieved on December 27, 2009 from http://plato.stanford.edu/entries/frame-problem/

Steffe, L. P., \& Thompson, P. W. (2000). Teaching experiment methodology: Underlying principles and essential elements. In Handbook of research design in mathematics and science education, A. Kelly \& R. Lesh, 267-306. Mahwah, NJ: Lawrence Erlbaum Associates.

Thompson, P. W. (1994). The development of the concept of speed and its relationship to concepts of rate. In The development of multiplicative reasoning in the learning of Mathematics, edited by G. Harel \& J. Confrey, 181-236. Albany, NY: State University of New York Press.

Walkerdine, V. (1982). From context to text: A psychosemiotic approach to abstract thought. In Children thinking through language, edited by M. Beveridge, 129-155. London: Edward Arnold.

Zandieh, M. J., \& Knapp, J. (2006). Exploring the role of metonymy in mathematical understanding and reasoning: The concept of derivative as an example. Journal of Mathematical Behavior 25(1), 117.

\section{About the Authors:}

David Kirshner is professor of mathematics education at Louisiana State University. His research interests include the psychology of algebraic symbol skills, and the relations of pedagogical practice to psychological theory. He may be emailed at dkirsh@lsu.edu.

Stephen Lerman is professor of mathematics education and Deputy Director of the Centre for Educational Research in the Department of Education at London South Bank University. His research interests focus on the social turn in pedagogical theory and learning theory. He may be emailed at lermans@lsbu.ac.uk.

Thomas Ricks is assistant professor of mathematics education at Louisiana State University. His research interests focus on the complex and fractal constitution of engagement in the mathematics classroom. He may be emailed at tomricks@lsu.edu or contacted at www.TOMRICKS.com. 
DAVID KIRSHNER, STEPHEN LERMAN \& THOMAS E. RICKS

(C) Copyright 2010. The authors, DAVID KIRSHNER, STEPHEN LERMAN, AND THOMAS E. RICKS, assign to the University of Alberta and other educational and non-profit institutions a non-exclusive license to use this document for personal use and in courses of instruction provided that the article is used in full and this copyright statement is reproduced. The authors also grant a non-exclusive license to the University of Alberta to publish this document in full on the World Wide Web, and for the document to be published on mirrors on the World Wide Web. Any other usage is prohibited without the express permission of the authors. 